\title{
Patrimônio e matrimônio: proposta para uma nova historiografia da cultura ocidental
}

\section{Patrimony and matrimony: proposing a new historiography of Western culture}

\author{
Ria Lemaire*
}

\begin{abstract}
RESUMO
Desde os anos 70 do século XX, os estudos sobre a mulher e gênero trouxeram para o campo da historiografia ocidental, além de inúmeras provas das contribuições das mulheres para a cultura, obliteradas ou distorcidas pela historiografia oficial, uma visão bem completa das estratégias de exclusão, apropriação, perseguição e mutilação desse matrimônio, com o objetivo de perpetuar a visão do patrimônio cultural como superior, único e exclusivamente masculino. Urge a criação de uma nova historiografia, baseada numa arqueologia desse conhecimento histórico convencional, na sua revisão com critérios científicos e inserção em novos quadros históricos que mostrem e questionem continuamente, de maneira igualitária, as contribuições patrimoniais e matrimoniais para a história da cultura ocidental.
\end{abstract}

Palavras-chave: Historiografia. Educação feminina. Autoglorificação. Desvalorização.

\begin{abstract}
Since the 1970s, women's and gender studies have brought to the field of Western historiography (as well as numerous proofs of women's contributions to culture, obliterated or distorted by official historiography), a very comprehensive view of exclusionary strategies, appropriation, persecution and mutilation of this matrimony, all of which aim at perpetuating the view of cultural heritage as a superior, unique and exclusively male patrimony. We urgently need the creation of a new historiography, based on an archeology of the genesis of this conventional historical knowledge, on its revision with scientific criteria, and its insertion in new historical frameworks

* Université de Poitiers. Centre de Recherches Latino-Américaines. Poitiers, França. E-mail: rialemaire@hotmail.com. https://orcid.org/0000-0003-3215-7830.
\end{abstract}


that continually show and question, in an equal way, the patrimonial and matrimonial contributions to the history of Western culture.

Keywords: Historiography. Women's education. Self-glorification.

Devaluation.

En la fuente del rosel

lavan la niña y el doncel

En la fuente de agua clara con sus manos lavan la cara

él a ella y ella a él:

lavan la niña y el doncel.

Autor anônimo (Século XV)

\section{Uma tradição indo-europeia}

Há muitos anos atrás, no Caminho do Norte - a grande rota dos peregrinos dos países nórdicos para Santiago de Compostela -, cheguei, de mochila nas costas, na linda aldeia Domrémy-la-Pucelle, onde nasceu Joana d'Arc, heroína da Guerra dos Cem Anos (1337-1453) entre dinastias francesas e o reino da Inglaterra. Joana, acusada de bruxaria, foi queimada viva na cidade de Orléans em 1431 e beatificada pelo Papa Pio X em 1909. Todos os anos, a aldeia comemora a sua heroína durante a Festa da Árvore de Maio. Assisti às festas, uma mistura de tradições antiquíssimas com "modernidades" bem ou mal integradas. Foi assim que redescobri, in vivo, as danças primaveris das quais falam os manuscritos da Idade Média europeia. Eram rodas de mulheres em torno da Árvore de Maio que as minhas avós e tias-avós, no século XX, ainda evocavam de vez em quando com saudade.

Em Domrémy, nos anos 1970, as mulheres jovens, em idade núbil, perpetuavam a roda, ritual pré-cristão de fertilidade e fecundidade. Elas bailavam e cantavam, apesar de estarem esquecidas (depois de 2000 anos de difamações da mulher e da sexualidade pela Igreja Católica) da conotação erótica e a antiga função, altamente sexuais e provocadoras, da roda. Desde os tempos primaveris mais remotos, foi isto que as mães ensinavam para as filhas: formar um círculo, dar as mãos, bailar em torno de uma árvore sagrada (Árvore de Maio: tília, aveleira, romãzeira etc.), cantar os refrãos ensinados pelas anciãs, repeti-los, retomando os seus ritmos e rimas para improvisar novos versos. Celebrar a vida 
que renasce, exibir a sua juventude, beleza e atração sexual, seduzir os namorados. Poesia dialogada do Passado, cantada e bailada, memorizada e improvisada, reinventada no Presente num ritual que preparava o Futuro da comunidade.

Para compreender a importância desse fenômeno cultural para o tema da História da Educação, é preciso conhecer melhor o mundo cultural indo-europeu que era baseado numa divisão do trabalho econômico entre os sexos e que necessitava, de um lado, a convivência dos homens (proteção da aldeia, guerra, caça, educação dos jovens masculinos etc.) e, do outro lado, a das mulheres (agricultura, vida doméstica, educação das filhas e dos filhos enquanto pequenos etc.). Dois tipos de convivência e de educação complementares que geraram dois mundos culturais com práticas, usos e costumes, conivências, cumplicidades, linguagens, cantos, contos, jogos e danças bem diferentes. Com duas "literaturas" diferentes que, resumidas globalmente, são a lírico-narrativa das mulheres e a épico-narrativa dos homens. (KATONA, 1979; LEMAIRE, 1994).

\section{Cem cantigas galego-portuguesas}

Um corpus medieval de umas cem cantigas de amigo paralelísticas dialogadas galego-portuguesas é, na Península Ibérica, o que mais reminiscências oferece do mundo das mulheres de outrora. Baseava-se numa concepção cósmica e mágica do mundo, naquele conhecimento ou "ciência" complexa das interconexões e interações cósmicas entre todos os componentes do universo. Trata-se de um conhecimento ancestral profundo, ao mesmo tempo prático, concreto, mental, espiritual e mágico. A sua aprendizagem fazia parte das atividades da vida cotidiana. Integrado nelas, ele é, antes de mais nada, um fazer (MALINOWSKI, 1925) e um agir (JOUSSE, 1925), mas que tem sido, desde a Idade Média até agora, vilipendiado e perseguido pelos poderes públicos e eclesiásticos como sendo heresia e superstição.

Possuir essa sabedoria ancestral era a conditio sine qua non para poder fazer bem os gestos, atos e ritos capazes de influenciar a natureza, as pessoas, a vida e os acontecimentos. A linguagem poética das cantigas veicula, sob forma de metáforas, essa ciência feminina que ensina que um ato concreto (bailar, ou beber a água da fonte, ou lavar-se com essa água, ou colher uma rosa) permite estabelecer conexões com o cosmos. Assim, para a realização das bailadas primaveris, as mulheres trocavam todos os anos os seus conhecimentos sobre a vida sexual e a procriação; tornavam-se cúmplices no momento em que elas iam enfrentar o mundo dos homens para um ritual erótico-mágico cujo objetivo era 
ao mesmo tempo individual (o prazer sensual e lúdico) e social (a sobrevivência e coesão social da comunidade).

Uma dessas rodas bailadas é um diálogo entre uma mãe e uma filha, atribuído pela História da Literatura a um clérigo (sic) galego, chamado Airas Nunes. Os versos revelam os objetivos erótico-mágicos da dança primaveril, ilustrando a transmissão, de mãe para filha, de conhecimentos relacionados com o desejo sexual, o erotismo, a procriação e o amor. A estrutura das quatro estrofes conservadas nos cancioneiros salienta bem esse papel de educadora desempenhado pela mãe. É ela quem canta os primeiros dois versos de cada estrofe. Esses dísticos maternos começam por uma ordem dada sob forma de imperativo (LIRA; LEMAIRE, 2014, p. 117):

"Bailade"

- Bailade, oje, ai filla, que prazer vejades ant'o voss'amigo, que vós moit'amades.

- Bailarei eu, madre, pois me vós mandades, mais pero entendo de vos ua ren: de viver el pouco muito vos pagades, pois me vós mandades que baile ant'el ben.

A primeira estrofe apresenta os três temas do ritual do dia interligados, a saber: dança, erotismo e namoro. Trata-se de uma associação muito comum na arte da Idade Média, como o ilustra, por exemplo, o pequeno tríptico na fachada de uma igreja românica (Figura 1).

\section{FIGURA 1 - FACHADA DA IGREJA DE SÃO CIPRIANO}

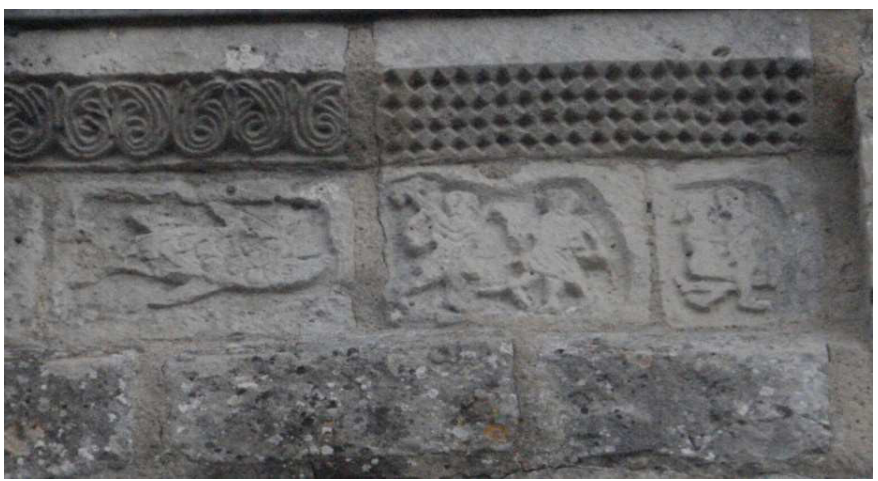

$\mathrm{Na}$ fachada da igreja românica mais antiga (XIe) da pequena cidade de Melle, no Sul-Oeste da França, ensina-se até hoje como conectar desejo sexual (o símbolo do peixe), dança e procriação. FONTE: foto tirada por Ria Lemaire, 2018. 
Desde o segundo verso, a mãe evoca também o objetivo da bailada que é a sedução, a provocação sexual do namorado: "Bailade ante o vosso amigo". O bailar será a iniciativa da mulher, um ato ao mesmo tempo concreto, alegre, prazeroso, sensual, lúdico e uma metáfora, um gesto simbólico pelo qual a jovem convida e incita o namorado para ser o seu parceiro nos rituais das festas primaveris.

A reação positiva da filha ("bailarei eu"), mas reticenciosa ("pois"), vem num dístico com a mesma rima (mandades/pagades) e com dois versos intercalados que constituem o refrão que reforça ainda mais a sua reticência ("mais pero"). Lá onde o ensino dado pela mãe se constrói bem didaticamente, com um novo elemento a cada estrofe, a reação da filha não evoluirá. Com ligeiras variantes, ela repete que obedecerá à ordem, mas que a mãe tem que saber que isso pode causar a "morte" do namorado; ele vai "viver pouco" (morrer), ou, como diriam outras cantigas do mesmo corpus de cantigas dialogadas, "morrer de amores"!

Nesse contexto as quatro respostas da filha são, na verdade, quatro piscares de olhos, ou seja, parte de uma brincadeira de filha e mãe coniventes. Trata-se de um jogo de palavras chistoso em torno de uma expressão frequente no vocabulário da cantiga de amigo, a saber: morrer d'amor(es), como se ouve, por exemplo, noutra cantiga dialogada entre mãe e filha (LEMAIRE, 1988, p. 174):

De que morredes, filha, a do corpo velido?

Madre, moiro d'amores que me deu meu amigo.

É a metáfora "morrer" que evoca nas cantigas a pulsão, o desejo sexual intenso, tanto da mulher quanto do homem. Ela alude à excitação do desejo que a filha vai provocar no namorado até o seu cumprimento sagrado nos quadros do ritual para o qual a bailada constitui o prae-ludium, o jogo alegre que prepara para a êxtase da parte sagrada do ritual.

Na segunda estrofe, a mãe dá ênfase a esse caráter sagrado do ritual que a jovem vai cumprir: "Rogo-vos por Deus". A alusão à beleza da filha, - "ben parecedes" -, ao estimular a sua autoestima, autoconfiança e autoerotismo, reforça um conselho importante: o de ela ser sexualmente ativa (LIRA; LEMAIRE, 2014, p. 117):

- Rogo-vos, ai filla, por Deus, que bailedes ant'o voss'amigo, que ben parecedes.

- Bailarei eu, madre, pois mi-o vós dicedes mais pero entendo de vos ua ren: de viver el pouco gran sabor avedes, pois que me mandades que baile ant'el ben. 
A valorização do corpo e da beleza da mulher constituía uma estratégia pedagógica básica da educação da mulher no mundo indo-europeu, antes da chegada do catolicismo que conseguiu diabolizar a sexualidade, culpabilizar a mulher e transformar o ato sexual em pecado. Vivida no segredo da casa da família nuclear e do casamento monogâmico, fora da vida social da comunidade, essa "nova" sexualidade impôs à mulher o dever de ser sexualmente passiva, de se sentir culpada e esperar, submissa, as iniciativas do dono-proprietário: da casa, dela e dos seus filhos. A riqueza e a variedade do vocabulário das cem cantigas de amigo paralelísticas no campo da beleza testemunham um saber e uma sabedoria que só hoje em dia as mulheres redescobrem e reconquistam progressivamente: a da autoestima, da autoconfiança e da desculpabilização como conditio sine qua non de uma vida sexual harmoniosa, humana e feliz. As mulheres das cem cantigas medievais sabiam disso; elas dizem e repetem a si próprias e às outras mulheres: bela, loada, velida, fremosa, louçana, delgada, a do bon parecer, a do bon semelhar, la ben talhada, fremosa de bon parecer etc.

$\mathrm{Na}$ terceira estrofe da bailada, a mãe traz novo ensinamento: o do caráter mágico do ritual de procriação quando alude ao lugar da bailada que vai ocorrer debaixo da "milgranada", a árvore sagrada cuja fruta é a romã, a fruta mágica das mil sementes, símbolo arcaico da fecundidade e procriação (LIRA; LEMAIRE, 2014, p. 117):

- Por Deus, ai mia filla, fazed'a bailada ant'o voss'amigo, de so a milgranada.

- Bailarei eu, madre, d'aquesta vegada, mais pero entendo de vos ua ren: de viver el pouco sodes mui pagada, pois me vós mandades que baile ant'el ben.

A "aula" da mãe termina, na quarta estrofe, com outro argumento forte e concludente que é o do amor recíproco ("querer bem") dos dois jovens, já testemunhado pelo namorado no passado, e que vai obter agora, "oj", a sua confirmação social e sacralizada perante toda a comunidade através da bailada debaixo da romãzeira (LIRA; LEMAIRE, 2014, p. 117):

- Bailade oj', ai filla, por Sancta Maria, ant'o voss'amigo, que vos ben queria.

- Bailarei eu, madre, por vós todavia, mais pero entendo de vós ua ren: en viver el pouco tomades perfia, pois que me mandades que baile ant'el ben. 


\section{Dois mundos, duas educações}

Essa cantiga de amigo dialogada da tradição indo-europeia está transcrita e salvaguardada em dois manuscritos de poesia medieval galego-portuguesa. Ela ilustra tanto o conteúdo quanto o funcionamento da educação sexual das jovens em idade núbil. Ela é considerada lúdica no sentido em que o filósofo holandês Johan Huizinga definiu o "lúdico sério" das civilizações tradicionais num grande clássico da literatura filosófica do século XX, Homo ludens (HUIZINGA,1996). Esse jogo prazeroso, erótico e ritualizado é também intelectual e artisticamente instigante; a comunidade vai saber quem improvisa e canta os versos mais bonitos, quem baila com mais graça e sedução. Todas essas funções são assumidas em poucos versos, reduzidos à essência da mensagem, que é transmitida através da estratégia discursiva da repetição com ligeiras variantes progressivas.

Descobrimos aqui as estratégias didáticas principais da transmissão do conhecimento feminino nas civilizações da oralidade, a saber: a repetição com variantes, a instigação lúdica e prazerosa das aprendizes e o ensinar e aprender fazendo, pela experiência e a troca de experiências e conhecimentos. Outra estratégia fundamental é a da ativação do corpo que se torna, pelos movimentos e gestos ritmados do trabalho cotidiano ou da dança e pelas modulações da voz, coprodutor e depositário dos novos conhecimentos, ao enraizá-los não só na mente-memória como também no corpo-memória. $\mathrm{O}$ apelo à emoção e à empatia das participantes, a valorização da sua beleza e o reforço de sua autoestima e confiança reforçam a estratégia primária dos movimentos ritmados da dança (LIRA; LEMAIRE, 2014). Assistimos à transformação de um conhecimento racional, mental em um "saber", muito mais complexo e abrangente, que engaja o ser humano todo numa unidade indissociável de corpo e alma.

A transmissão desse saber secular feminino impressiona pela sobriedade, concisão e precisão das palavras, contrariamente aos gêneros épico-narrativos do mundo masculino que são muito mais prolixos ao trazerem inúmeros pormenores e detalhes. Funcionalidade e funcionamento da poesia masculina são diferentes da canção feminina, concentrando-se nas horas de lazer, de descanso, à noite, depois da caça ou da guerra. Os versos masculinos não têm essa função básica e física de tornar o trabalho cotidiano mais leve, mais agradável, a dança mais sensual e atraente. Os cantos épicos preenchem as horas de lazer masculino, alimentando e glorificando a memória do heroísmo, das façanhas, da força física, da coragem e da astúcia da classe socioeconômica do guerreiro-caçador, defensor e protetor da comunidade. O seu objetivo, além da educação dos jovens guerreiros, 
é fortalecer e legitimar a sua posição de destaque na comunidade pela repetição e reinvenção incessantes das grandes ações e façanhas do passado. Mitificados progressivamente (hoje em dia se diria ficcionalizados) pela invenção e pelo acréscimo contínuo de novos pormenores heroicos, essas narrativas transmitirão aos jovens os modelos de comportamento para o guerreiro-caçador, protetor e defensor da comunidade.

A veia épico-narrativa masculina comporta vários gêneros monologados, tais como a epopeia, o romance guerreiro e a genealogia, cantados a capela ou declamados com um simples acompanhamento fixo musical (toada). A sua performance realizando-se nas horas de lazer, a sua base é a palavra poética do verso declamado pelo cantador/declamador, cuja função é convencer e seduzir um público de ouvintes ${ }^{1}$. Comparada à poesia feminina, a poesia épico-narrativa oferece as ferramentas pedagógico-didáticas para um tipo de educação bem diferente, sendo que a aquisição do conhecimento do Passado histórico - e das invenções acrescentadas! - tornou-se predominantemente mental. É outra forma de educação, já que o conhecimento não é coproduzido por educadores e aprendizes no decorrer de um processo cognitivo baseado na unidade e cooperação de corpo, mente, emoção e espírito. Ela é monólogo declamado por um poeta que comunica o conhecimento a um círculo de ouvintes-aprendizes; produção e recepção são dois processos separados. A linguagem poética ritmada, os versos declamados ou cantados ensinam no Presente não a experiência e a verdade dos eventos da vida vivida no passado, mas uma narrativa (WHITE, 1973) que reinventa e amplifica um Passado mitificado, não só para educar novos heróis para o Futuro da comunidade toda, como também para fortalecer e perpetuar a posição social, o poder e os interesses da elite guerreira masculina da qual eles vão fazer parte.

É uma educação baseada numa estrutura mental, racional e radicalmente dicotômica: a separação de corpo e mente/alma, de produção e recepção do conhecimento, corresponde a dicotomias, tais como heroísmo versus covardia, o Bem contra o Mal, força contra fraqueza, vencedores contra vencidos. Ela transmite valores morais que glorificam a força física do indivíduo, a coragem e a astúcia do homem predador que luta e mata (o animal da caça, o rival, o adversário, o inimigo) e celebram a morte do herói como sacrifício supremo

1 O mundo dos homens pratica também vários gêneros de poesia narrativa, tanto monologada quanto dialogada - desafio ou repente - sobre os temas mais variados: escárnio, conhecimentos/ ciência, novidades, religião, sexo, atualidade, desastres, milagres etc. O repente dos violeiros nordestinos, desde finais do século XIX, era impresso sob forma de folheto e chamado de literatura de cordel pelos eruditos, constitui um interessante exemplo de uma poesia narrativa tradicional, produzida e reproduzida por poetas/cantadores e cantadoras de todas as camadas sociais da comunidade tradicional. (NOBRE, 2017; SANTOS, 2018). 
ao serviço da comunidade. A gabação e a glorificação dessas qualidades de guerreiro educam os homens jovens para serem rivais, concorrentes uns dos outros, até no seio da sua própria comunidade e em relação às mulheres! O fascínio pela morte (do guerreiro inimigo, do animal perseguido), a depredação dos bens dos adversários e o rapto e/ou estupro das suas mulheres como armas de guerra - uma sexualidade vista e vivida como apropriação pela força física e violência do corpo de mulheres desconhecidas e submetidas - constituem códigos e modelos de comportamento masculino.

Ao comparar as caraterísticas das duas veias poéticas, detecta-se mais uma função social das rodas primaveris que corresponde a uma necessidade vital, cósmica para a procriação de novas vidas nas comunidades tradicionais, a saber: disciplinação, socialização, erotização e ritualização; isto é, educação, da violência masculina sexual e guerreira que constitui ao mesmo tempo a base da proteção e defesa de toda comunidade, mas também uma ameaça para as mulheres e a procriação humana e harmoniosa.

É importante se dar conta do fato de que a poesia lírica e épica - e a poesia narrativa em geral - constituem, nas sociedades orais e ágrafas, formas básicas de transmissão do conhecimento e da educação, sendo que não existiam livros-manuais, nem "escola", nem sistema de ensino formal - no sentido moderno da palavra -, como explica o grande poeta nordestino Patativa do Assaré (19092002), ao declamar para o seu entrevistador Gilmar de Carvalho o poema "Meu Campina" (CARVALHO, 2002, p. 21-24):

Sem puder fazer escolha de livro artificial aprendi nas lindas folha do meu livro natural.

\section{De dois mundos complementares a um monopólio masculino}

O mundo lírico-narrativo das mulheres e o mundo épico dos homens, ao mesmo tempo complementares e antagônicos, têm de fato leituras diferentes do "livro da natureza". Para as mulheres é a concepção cósmica e a experiência do ser humano, como uma unidade indissociável de corpo e espírito/alma, num mundo mágico onde a sexualidade é sagrada. É a busca das conexões cósmicas para poder bem viver a vida num processo de cocriação de saberes e fazeres, correalizado por educadoras e aprendizes. É a aquisição do conhecimento pela 
realização lúdica, prazerosa, empática desse programa educacional, presente em todas as atividades cotidianas, fazendo apelo ao conjunto das capacidades físicas, mentais, emocionais e espirituais das aprendizes.

Os leitores masculinos do livro da natureza, devido à sua posição socioeconômica diferente, aprenderam nele a separação de corpo e mente/alma no processo da transmissão do conhecimento e concepção do seu ensino, não como a busca da verdade sobre o Passado e a vida, mas como comunicação de uma visão mítica, dicotômica deles, a serviço dos interesses da classe guerreira do Presente e da perpetuação da sua posição privilegiada no Futuro. A transmissão e a aprendizagem do conhecimento são hierárquicas e baseiam-se em duas estratégias narrativas interligadas: a amplificação dos fatos positivos, heroicos e a obliteração dos fracassos; e, quanto aos protagonistas, por um lado, a glorificação e o enaltecimento do herói guerreiro e da sua linhagem, por outro, a diminuição e o descrédito dos seus inimigos² ${ }^{2}$.

Não é difícil de enxergar, desde já, qual dos dois tipos de "leitura da natureza" estão disponíveis desde as origens da civilização ocidental e que adquirirá progressivamente o monopólio no mundo moderno, tornando-se o modelo único do conhecimento, da ciência, da educação e da sua historiografia única e oficial. A Idade Média, em todos os domínios da vida humana, ainda mantém inúmeros usos, práticas e estruturas (linguísticas, sociais, culturais, científicas) que lembram a existência de dois mundos mais ou menos independentes mas complementares: o dos homens e o das mulheres, de duas linhagens, educações, literaturas, ciências, medicinas e vivências religiosas. (CALADO, 2015).

Havia ainda, de um lado, um patrimônio no sentido de bens materiais e culturais da linhagem masculina, transmitidos de pai para filho; e, de outro lado, um matrimônio no sentido originário do termo: conjunto dos bens materiais e culturais pertencentes à linhagem feminina. Na língua francesa, ainda no século $\mathrm{XV}$, a palavra matrimônio mantém seu sentido original de bens maternos ao lado do significado mais recente, o de casamento, que se propaga progressivamente no decorrer da segunda era medieval como acompanhante da instalação do casamento monogâmico (DUBY, 1981) para se generalizar nos tempos modernos, fazendo esquecer aos povos o sentido original da palavra.

A história dos dois mundos, para quem puser as lentes da questão de gênero, desenrola-se como uma evolução paralela em direções opostas, ao mostrar o

2 Existem também práticas de troca e partilha, momentos e eventos de intercâmbio das duas culturas. Antropólogos e etnólogos confirmam que cerca de 10\%, globalmente, das poesias do mundo das mulheres passa para o dos homens também e inversamente. Desterritorializados, esses textos adotarão aos poucos caraterísticas do seu mundo de adoção, transformando de forma gradual, por exemplo, um romance épico-narrativo com herói masculino em lírico-narrativo com protagonista feminina. 
lento e progressivo declínio e silenciamento do matrimônio e a monopolização progressiva do patrimônio. As mulheres indo-europeias antigamente tinham um riquíssimo matrimônio, poderes, estatuto, direitos e prerrogativas. Um momento político crucial para a conquista do monopólio masculino foi o ano 325, ano do Primeiro Concílio de Niceia, convocado pelo imperador romano, Constantino I, recém-convertido ao cristianismo. De seita perseguida, a Igreja de Roma se transformou em religião oficial de um império. Nasceu a aliança do poder público leigo com o poder eclesiástico, representado pelos dirigentes masculinos, profundamente misóginos, da Igreja Católica. Aliança de duas classes sociais da elite: a dos homens predadores e seus aliados e a dos pregadores, que vai desencadear no planeta Terra uma luta pelo poder, sem tréguas nem fim, contra o sexo feminino e contra todos aqueles homens (quer dizer a grande maioria do sexo masculino!) que não pertencem à nobreza ou à Igreja e seus aliados.

Ao analisarmos a historiografia oficial dessa aliança institucionalizada de poder político público e eclesiástico com as lentes da meta-história (WHITE, 1973), como um processo de narrativização, baseado na seleção, organização, estruturação e estetização do corpus de dados disponíveis, detecta-se logo o funcionamento das suas estratégias de ficcionalização da realidade/verdade. Desde a Idade Média, Fernão Lopes (1418-1459), cronista/historiógrafo oficial do rei de Portugal, ao ditar o prefácio da sua Crónica de D. João I (1443), constata que a historiografia impõe uma seleção prévia dos fatos históricos, motivada pela necessidade do enaltecimento das façanhas do comitente, detentor do poder político, e da redução ao mínimo ou obliteração dos seus fracassos (LOPES, 1443, pref.): "[...] louvando-a dizem sempre mais daquele que é; e, se doutro modo, nom escrevem suas perdas tam minguadamente como aconteceram [...]".

Uns séculos mais tarde, a monja Anne de Saintonge (1567-1621), ao pedir ao Papa de Roma a autorização para criar uma ordem religiosa de mulheres, dedicada à educação feminina, diplomaticamente explica ao papa, na Constituição 15 da Ordem, que esse ensino, de jeito nenhum, interferirá com o monopólio do ensino masculino, baseado no enaltecimento das façanhas masculinas (SAINTONGE, s.d., não p.): "Les soeurs ne porteront pas de grands flambeaux qui jettent un jour brillant dans l'Eglise, mais de petites lampes qui éclaireront les jeunes filles, les servantes, les pauvres et les femmes, pour faire connaitre et adorer Dieu par son divin Fils Notre Seigneur"”.

Já no século XX, Miguel de Unamuno (1864-1936), um dos grandes pensadores da identidade nacional espanhola, no auge da formação do estado-nação espanhol, confirma e elogia o caráter ficcional da historiografia oficial.

3 Tradução da autora: As irmãs não ostentarão grandes tochas que projetam uma luz brilhante na Igreja; mas pequenas lâmpadas que iluminarão as meninas jovens, as empregadas, os pobres e as mulheres para que conheçam e adorem Deus, através do seu Filho divino, o nosso Senhor. 
Num artigo de jornal, conservado e exposto (sem data) na Casa de Unamuno em Salamanca, ele a qualifica como "espiritual" ao explicar que o objetivo do escritor, também pensador e historiógrafo, é "fazer acreditar aos seres humanos" essa nova verdade escrita, inventada, que ele coloca bem acima da memória dos que viveram, contam e recontam oralmente a sua experiência dos acontecimentos: "Los monjes escribian en paz hechos de Guerra, y al escribir historia la hacian. Que el hecho histórico es espiritual y consiste en lo que a los hombres se les hace creer que queda de lo que pasó en la leyenda".

Na mesma fase histórica, e no estado-nação vizinho, o pensador Ernest Renan (1823-1892) sublinha o papel desse "fazer" a história ao apresentar como "essência" da nação a amnésia dos fatos históricos suscetíveis de manchar a sua reputação de perfeição, igualdade e justiça que seus historiadores têm que ensinar aos cidadãos: "Or l'essence d'une nation est que tous les individus aient beaucoup de choses en commun, et aussi que tous aient oublié bien des choses $^{4 \prime}$. (RENAN, 1947 [1882], p. 892).

Já no século XXI, um grupo de pesquisa do CNRS francês (Centro Nacional da Pesquisa Científica), dedicado à História dos Intelectuais, publica um livro sobre a história das mulheres intelectuais, intitulado Histoire des Intellectuelles. (RACINE; TREBITSCH, 2004). Os estudos nele incluídos põe o dedo na ferida já aberta pelas críticas pós-modernas do universalismo, scriptocentrismo, falocentrismo e nacionalismo, todos esses preconceitos que invalidam a "ordem dos discursos" (FOUCAULT, 1970) do mundo atual, sejam eles científicos, historiográficos ou outros, ao mostrar que os seus pressupostos, as suas motivações e valores subjacentes mais profundos são até hoje em dia a violência, sexual e guerreira, masculina: "Tout comme l'armée, davantage scrutée, les institutions masculines sécrètent une culture spécifique d'autoglorification et de dévalorisation du féminin ${ }^{5}$." (CHAPERON, 2004, p. 133).

\section{A historiografia oficial da educação pela roda feminina}

Quem for estudar na História da Literatura Portuguesa medieval o lugar da cantiga bailada da mãe e da filha, atribuída ao autor/clérigo galego Airas Nunes, descobrirá um processo complexo e perverso de apropriação do texto com o

4 Ora, a essência de uma nação é que todos os indivíduos tenham muitas coisas em comum e que todos tenham esquecido muitas outras.

5 Inteiramente como o exército, sobre o qual existem já mais investigações, as instituições masculinas secretam uma cultura específica de autoglorificação e de desvalorização do feminino. 
objetivo da sua inserção na História da Literatura Nacional Portuguesa que, nos séculos XIX e XX, como todas as outras histórias das literaturas nacionais dos estados-nações da Europa, precisava ser o produto do gênio masculino, do homem branco da alta sociedade burguesa nacional. A cantiga analisada está inserida no capítulo dedicado à literatura trovadoresca. Esses trovadores, homens da nobreza, com fina sensibilidade e uma intuição genial da alma feminina, teriam criado/escrito essas cantigas, pondo-as na boca de meninas simples, ingênuas e incultas do mundo rural. Existe um manuscrito do século XIII que recebeu o nome de Cancioneiro da Ajuda que contém mais de 300 cantigas de amor medievais e 16 iluminuras que mostram como funcionava essa poesia. Cada iluminura tem os mesmos protagonistas (Cf. Figura 2): um homem nobre, sentado (o suposto "autor" da cantiga) e dois artistas performáticos, jograis e jogralesas que cantam, tocam música e bailam.

\section{FIGURA 2 - ILUMINURA DE UM CANCIONEIRO MEDIEVAL (SÉC. XIII) QUE MOSTRA UM HOMEM NOBRE - TROVADOR - SENTADO E DOIS ARTISTAS-PERFORMERS}

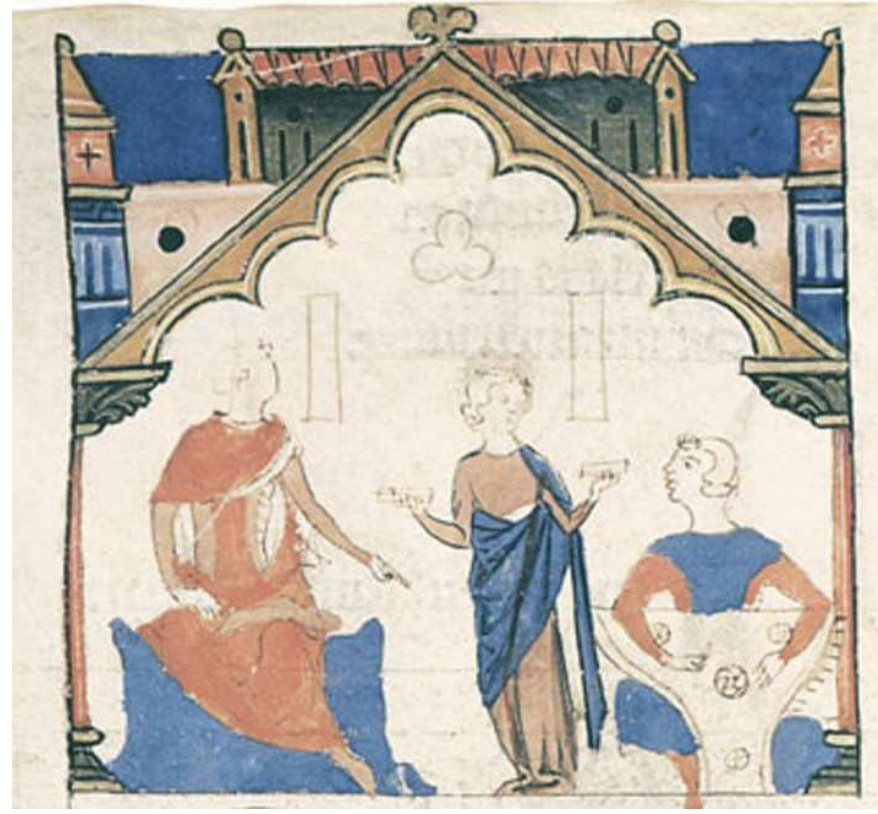

FONTE: Cancioneiro da Ajuda, século XIII.

Debaixo do termo mais ou menos neutro de atribuição ao autor/clérigo galego Airas Nunes, oculta-se toda uma série de estratégias de glorificação do 
gênio masculino e desvalorização da mulher como produtora cultural. Estratégias antiquíssimas e básicas da historiografia da civilização ocidental que obrigam até hoje em dia os fiéis da Igreja Católica a ler a linda recolha das cantigas da jovem namorada que "morre de amores" do Cântico dos Cânticos, no Velho Testamento, como uma criação individual, genial do rei Salomão, autor-escritor desse hino da Igreja terrestre ao seu Deus celeste.

A cantiga da mãe e filha, uma vez integrada na história da literatura portuguesa, não será mais uma coprodução feminina, oral e secular, mas uma obra única, escrita por um escritor masculino individual. Portanto, tornou-se produto da cultura escrita considerada superior. O seu produtor, clérigo, pertence às elites da sociedade; assim a cantiga entra também na genealogia "heroico-literária" que, desde a Ilíada e a Odisseia, "escritas" pelo poeta cego (sic) Homero, imortaliza as obras literárias escritas da humanidade e os seus escritores/autores. A cantiga foi "desterritorializada" não só histórica e culturalmente, como também socialmente ao passar do mundo rural ao mundo da corte, da cidade; e geograficamente quando os historiadores portugueses se apropriam das vozes das mulheres galegas para inseri-las na literatura portuguesa trovadoresca, cujo ideal amoroso é radicalmente diferente dos amores das mulheres-cantadoras.

Fin'amors cortês medieval caracteriza-se, na visão/narrativa dos historiógrafos dos séculos XIX e XX, pela desigualdade radical entre os dois parceiros. Esse ideal amoroso, apresentado pelos historiógrafos da literatura como o primeiro ideal de Amor da civilização ocidental, teria sido vivido em segredo, altamente individualizado, espiritualizado e associal. O desejo libidinal sempre insatisfeito o transformou em amor-sofrimento e infelicidade, causados pela ausência física do objeto do Amor. Isso sempre na visão mitificada dos historiadores do século XIX e XX, base da educação literária das jovens gerações destes séculos.

Observemos também a distorção do papel da mulher, ser humano sexualmente ativo, inteligente, sabido, educador e criador. Na historiografia oficial, as cantadoras transformaram-se em meninas inocentes, ingênuas e incultas que esperam passivas, tristes e ansiosamente o namorado ausente. Inúmeros corais ${ }^{6}$ famosos levaram aos palcos europeus, nos séculos XX e XXI, as suas rodas alegres, cantadas com vozes plangentes e choronas de vítimas passivas que esperam tristemente amantes ausentes, traidores e infiéis.

São essas vozes, distorcidas pelos historiógrafos oito e novecentistas, os modelos burgueses de comportamento feminino, que se escutam e divulgam em discos, CDs e concertos nos centros da cultura, e que se ensinam nas aulas de literatura dos países da lusofonia.

6 Consulta-se Martín Códax: Cantigas de Amigo - a discography: www.medieval.org/ emfaq/composers/codax.html. 


\section{Conclusão}

Entrei no meu jardim vi a rosa desabrochada. Tão docemente a colhi, a meu amigo a ofereci. ${ }^{7}$

Autor anônimo (século XV)

Já faz quase cinquenta anos que os estudos de mulher e de gênero praticam essa arqueologia do saber (no sentido em que Michel Foucault introduziu o termo) que nos permite, hoje em dia, não só fazer ressuscitar o matrimônio das mulheres, como também denunciar a sua historiografia oficial, ao inventariar os interesses econômicos, políticos e outros - as sexual politics (MILLETT, 1970) - que motivaram a sua obliteração e silenciamento. Foi uma aventura intelectual, ao mesmo tempo dolorosa e fascinante, que levou mulheres e muitos homens, ao seu lado, à descoberta da violência intrínseca dos discursos, científicos e outros, e das estruturas mentais dicotômicas que uma casta, constituída originalmente pela aliança das classes sociais de homens predadores e pregadores, no decorrer dos séculos, conseguiu embeber em todos os poros do nosso ser e mundo.

\section{FIGURA 3 - ATÉ A ROSA, O SÍMBOLO DO AMOR, TORNOU-SE VIOLENTA}

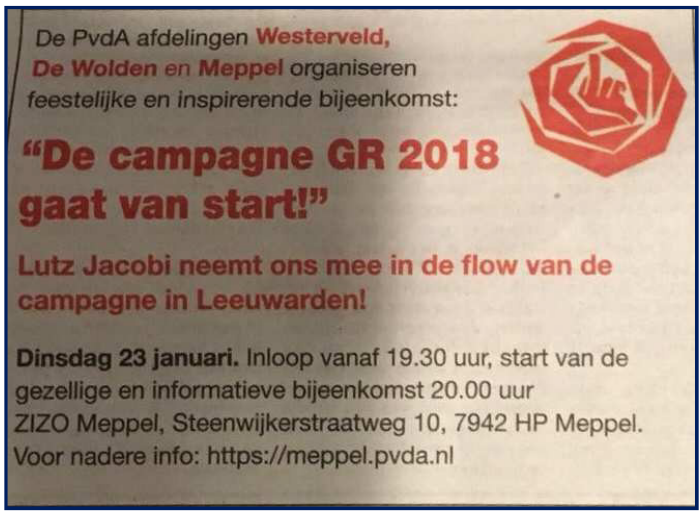

Cartaz do partido do trabalho da Holanda.

FONTE: eleições na Holanda em 2018.

7 Cantiga de amigo francesa do século XV: En no jardin je suis entrée/trouvay la rouse espanouye/sy doulcement je l'ay cuillie/et je l'ay donnée à mon amy. 
Por esse motivo, a historiografia do século XXI, para "fazer" História seja ela da sociedade, da literatura, das artes ou da educação -, não poderá se limitar a inserir simplesmente, em suas histórias convencionais, capítulos sobre o matrimônio restaurado. A consciência crítica trazida pelos estudos de mulher e de gênero obriga a uma cuidadosa "arqueologia do saber" patrimonial, pela desconstrução da sua onipresença e potência, dos seus pressupostos/preconceitos e mitos, com o objetivo de criar a base de uma historiografia que será (enfim!) científica. Ponto de partida para uma nova educação que conscientize sistematicamente os jovens sobre os defeitos e preconceitos da mainstream science que embasa todos os níveis da vida, do conhecimento e do ensino formal no mundo contemporâneo.

\section{REFERÊNCIAS}

CALADO, L. (Org.). As intelectuais na Idade Média: pensadoras, místicas, cientistas e literatas. João Pessoa: Ed. UFPB, 2015.

CARVALHO, G. Patativa, poeta pássaro do Assaré. Fortaleza: Omni Ed., 2002.

CHAPERON, S. Simone de Beauvoir à la croisée de l'histoire des femmes et des intellectuels. In: RACINE, N.; TREBITSCH, M. (Dir.). Intellectuelles: du genre en histoire des intellectuels. Paris: Complexe, 2004. p. 115-136.

CÓDAX, M. Cantigas de Amigo: a discography. Conception \& research: Pierre-F. Roberge. Disponível em: <www.medieval.org/emfaq/composers/codax.htm>. Acesso em: 9 out. 2017.

DUBY, G. Le chevalier, la femme et le prêtre. Paris: Hachette, 1981.

FOUCAULT, M. L'ordre du discours. Paris: PUF, 1970.

HUIZINGA, J. Homo ludens: o jogo como elemento da cultura. Trad. João Paulo Monteiro. São Paulo: Perspectiva, 1996.

JOUSSE, M. Etudes de psychologie linguistique: le style oral et rythmique chez les Verbo-moteurs. Paris: Beauchesne, 1925.

KATONA, I. Reminiscences of Primitive Divisions of Labour Between Sexes and Age Groups in the Peasant Folklore of Modern Times. In: DIAMOND, S. (Ed.). Towards a Marxist Anthropology. Den Haag: Mouton, 1979. p. 373-383.

LEMAIRE, R. Passions et Positions: contribution à une sémiotique du Sujet dans la poésie lyrique en langues romanes. Amsterdam: Rodopi, 1988. 
LEMAIRE, R. Repensando a história literária. In: BUARQUE DE HOLLANDA, H. Tendências e Impasses. Trad. Heloísa Buarque de Hollanda. Rio de Janeiro: Rocco, 1994. p. 58-78.

LIRA, S.; LEMAIRE, R. Cores do Atlântico-livro-CD das cantigas de amigo. Campina Grande: UEPB-Latus, 2014.

LOPES, F. Crónica de D. João I. Lisboa, 1443. [s.p.].

MALINOWSKI, B. The Problem of Meaning in Primitive Languages. In: OGDEN, K. C.; RICHARDS, I. A. The Meaning of Meaning. New York, 1925. p. 451-510.

MILLETT, K. Sexual Politics. New York: Doubleday, 1970.

NOBRE, F. A. Folhetos de cordel científicos - um Catálogo e uma Sequência de Ensino: Física, Astronomia e Matemática. São Leopoldo: Trajetos Ed., 2017.

RACINE, N.; TREBITSCH, M. (Ed.). Intellectuelles: du genre en histoire des intellectuels. Bruxelles: Complexe, 2004.

RENAN, E. Qu'est-ce qu'une Nation? [Conférence faite en Sorbonne, le 11 mars 1882]. In: RENAN, E. Euvres Complètes, t. 1. Paris: Calmann-Lévy, 1947. p. 891-892.

SAINTONGE, A. de. Constituição 15 da Ordem de Santa Úrsula. [s.d.; não p.].

SANTOS, F. P. dos. O Livro Delas: catálogo dos folhetos das mulheres cordelistas. 2018. No prelo.

WHITE, H. Metahistory: The Historical Imagination in Nineteenth-Century Europe. Baltimore: John Hopkins UP, 1973.

Texto recebido em 27 de março de 2018.

Texto aprovado em 18 de maio de 2018. 
